\title{
THE
}

\section{Comparative development and evolution of two lateral line phenotypes in Lake Malawi cichlids}

Jacqueline F. Webb

University of Rhode Island, jacqueline_webb@uri.edu

Nathan C. Bird

Lauren Carter

Juleen Dickson

Follow this and additional works at: https://digitalcommons.uri.edu/bio_facpubs

The University of Rhode Island Faculty have made this article openly available.

Please let us know how Open Access to this research benefits you.

This is a pre-publication author manuscript of the final, published article.

Terms of Use

This article is made available under the terms and conditions applicable towards Open Access

Policy Articles, as set forth in our Terms of Use.

Citation/Publisher Attribution

Webb, JF, Bird, NC, Carter, L, Dickson, J. 2014. Comparative development and evolution of two lateral line phenotypes in Lake Malawi cichlids. Journal of Morphology. DOI 10.1002/jmor.20247. 

PHENOTYPES IN LAKE MALAWI CICHLIDS

5 Jacqueline F. Webb*, Nathan C. Bird, Lauren Carter, and Juleen Dickson

9 *Corresponding author: Dr. Jacqueline F. Webb, Department of Biological Sciences, University

10 of Rhode Island, 120 Flagg Road, Kingston, RI 02881, USA. Email:

11 Jacqueline_webb@mail.uri.edu

12

13 Short Title: Development and Evolution of Cichlid Lateral Line

14 
17 ABSTRACT A comparison of the pattern and timing of development of cranial lateral line

18 (LL) canals and canal neuromasts in three species of Lake Malawi cichlids, Labeotropheus

19 fuelleborni and Metriaclima zebra (narrow LL canals), and Aulonocara baenschi (widened LL

20 canals) were used to test the hypothesis that the evolution of widened canals (an adaptive

21 phenotype in the lateral line system) from narrow canals is the result of heterochrony. Using

22 histological analysis and SEM, this study has provided the first detailed and quantitative

23 description of the development of widened lateral line canals in a teleost, and demonstrated that:

24 1) canal neuromast number and the pattern of canal morphogenesis are conserved among species

25 with different adult canal morphologies, 2) heterochrony ("dissociated heterochrony" in

26 particular) can explain the evolution of widened canals and variation in morphology between

27 canals in a species with respect to canal diameter and neuromast size, and 3) the morphology of

28 the lateral line canals and the dermal bones in which they are found (e.g., the mandibular canal

29 contained within the dentary and anguloarticular bones of the mandible) can evolve

30 independently of each other, thus requiring the addition of another level of complexity to

31 discussions of modularity and integration in the skull of bony fishes.

33 KEY WORDS: Cichlidae; neuromast; lateral line; heterochrony; modularity, dermatocranium,

34 hair cell 
For J. Morphol., February 8, 2014

\section{INTRODUCTION}

39 The mechanosensory lateral line system of fishes detects unidirectional and low frequency

40 oscillatory water flows and plays critical roles in prey detection and other behaviors (reviewed in

41 Webb, et al., 2008). Directionally sensitive neuromast receptor organs are distributed on the skin

42 (superficial neuromasts) as well as in canals (canal neuromasts) on the head, trunk and tail. The

43 cranial lateral line canals, which are integrated into a conserved subset of the dermatocranial

44 elements of bony fishes, demonstrate well-defined morphological variation among bony fishes

45 and among teleosts in particular (narrow, widened, reduced and branched canals; Webb, 1989b).

46 Narrow canals, the most common of the four canal morphologies, are well-ossified with small

47 pores that connect the fluid within the canal with the outside environment. In contrast, widened

48 canals have evolved convergently in only about a dozen families of typically benthic or deep-

49 water marine and freshwater teleosts. Widened canals are larger in diameter than narrow canals,

50 may cover much of the head, and typically contain large neuromasts. The canal roof is weakly

51 ossified and dominated by large bony canal pores, which are covered by an epithelium that is

52 pierced by very small "epithelial pores" that provide the connection between the fluid within the

53 canal and the external environment. Narrow and widened cranial lateral line canals have been

54 shown to be functionally distinct (Webb, et al., 2008; Denton and Gray, 1988, 1989) and it has

55 been suggested that the evolution of canal morphology among teleosts is the result of

56 heterochrony, or evolutionary changes in developmental timing (Webb 1989a). The study of

57 closely related species with narrow and widened canals provide an interesting context for the

58 integrative study of the adaptive evolution of the lateral line system, but it requires detailed

59 analyses of lateral line development. 
For J.Morphol., February 8, 2014

The development of the lateral line system has been studied in detail in only a small number

61 of species, all of which have narrow canals. It has been described as occurring in three phases

62 [5]. Migration of neuromast primordia from the cranial lateral line placodes establishes spatial

63 patterning of neuromasts in embryos and early larvae (as elegantly detailed in the posterior

64 lateral line system of zebrafish, Danio rerio; reviewed in Nunez et al., 2009; Aman and

65 Piotrowski, 2011; Chitnis et al., 2011). Then development continues with neuromast growth

66 (increase in size, change in shape) revealing distinctions between presumptive canal neuromasts

67 (those that will eventually become enclosed in canals) from other superficial neuromasts (that

68 will remain on the skin; e.g., Webb and Shirey, 2003). Finally, in late stage larvae,

69 morphogenesis of the lateral line canals is initiated around individual canal neuromasts to

70 initially form tubular canal segments, a process that occurs in four stages (Webb and Shirey,

71 2003; Tarby and Webb, 2003): Stage I - neuromast differentiates in the epithelium, Stage II -

72 neuromast sinks into an epithelial depression and then canal walls emerge from the dermal bone

73 below the neuromast and ossify, Stage III - epithelium encloses the neuromast forming a canal

74 segment, and Stage IV - ossified canal walls meet over the neuromast forming the ossified canal

75 roof. As they are forming, canal segments are increasing in diameter (Tarby and Webb, 2003;

76 Moore and Webb, 2008). Adjacent segments are also growing towards one another and fuse

77 leaving a common pore between them (e.g., Allis, 1889), thus accounting for the alternating

78 positions of neuromasts and pores along the length of the cranial canals in most bony fishes

79 (Webb and Northcutt, 1997).

80 The hypothesis that heterochrony can explain phenotypic evolution in the lateral line system

81 of bony fishes has been posed (Webb, 1989b; Webb, 1990), but not explicitly tested. The

82 evolution of reduced and branched cranial lateral line canals from narrow canals has been 
For J. Morphol., February 8, 2014

83 hypothesized to be the result of the simple truncation/deceleration (paedomorphic trend) or

84 extension/acceleration (peramorphic trend) of canal morphogenesis, respectively (Webb, 1989b).

85 In contrast, the evolution of widened canals appears to be the result of "dissociated

86 heterochrony", defined as a mixture of the evolution of peramorphic and paedomorphic features

87 (McNamara, 1997). For instance, the larger neuromasts and larger diameters that characterize

88 widened canals (reviewed in Webb, 2013) are hypothesized to be peramorphic features, while

89 the reduction in canal ossification that results in the large canal pores bounded by bony bridges

90 (as opposed to a solid canal roof pierced by small pores) of widened canals are hypothesized to

91 be a paedomorphic feature. The mechanisms underlying observed heterochronic change likely

92 include changes in osteoblast and osteoclast activity that alter the timing and/or pattern of

93 ossification of the canals, and/or changes in rates of hair cell differentiation from support cells

94 that result in differences in the size and shape of hair cell populations, and thus neuromast

95 morphology. Changes in gene expression and/or the action of gene products involved in these

96 processes could explain differences in adult canal and neuromast morphology. Such differences

97 are hypothesized to occur via heterochrony, but alternatively, changes in gene expression (or

98 action of gene products) could cause dramatic morphological differences in early larvae followed

99 by isometric increases in canal diameter and neuromast size relative to fish size.

100 Any study of the developmental basis for evolutionary change in phenotype requires the

101 availability of complete ontogenetic series from closely related species that have the phenotypes

102 of interest. The study of the development of widened lateral line canals, in particular, has been

103 hampered by the fact that the small number of taxa with widened canals (Webb, 2014) are

104 largely inaccessible for study and/or are particularly difficult to rear in the laboratory. The

105 speciose and diverse cichlid fishes provide an important opportunity to test a hypothesis of 
106 heterochrony in the evolution of the cranial lateral line system. They typically have narrow 107 cranial lateral line canals (Tarby and Webb, 2003; Branson, 1961; Peters, 1973; Webb, 1989c),

108 but among the endemic Lake Malawi cichlids, Aulonocara, Alticorpus and Trematocranus have

109 widened lateral line canals (Konings, 1990, 2007). Like other Lake Malawi cichlids that have

110 proven to be excellent subjects for comparative analyses of functional morphology and

111 development (Albertson and Kocher, 2001, 2006; Albertson, et al., 2001, Streelman, et al.,

112 2003; Hulsey et al., 2005; Sylvester et al., 2010), Aulonocara spp. (peacock cichlids; Meyer et

113 al., 1987) are particularly easy to maintain and rear under laboratory conditions. Furthermore, in

114 contrast to other cichlids, which are generally considered to be visual predators, Aulonocara uses

115 its lateral line system to detect water flows generated by benthic invertebrate prey living in sandy 116 substrates (Konings, 1990; Schwalbe, et al., 2012). In this study, a comparison of the pattern and

117 timing of development of cranial lateral line canals and canal neuromasts in Labeotropheus

118 fuelleborni and Metriaclima zebra (narrow canals) with Aulonocara baenschi (widened canals)

119 were used to test the hypotheses that the evolution of widened canals is the result of

120 heterochrony.

\section{MATERIALS AND METHODS}

124 The three study species, Labeotropheus fuelleborni, Metriaclima zebra, and Aulonocara

125 baenschi (referred to by genus throughout), were reared at $27.8^{\circ} \mathrm{C}$ with a $12: 12$ light cycle in a 126 multi-tank re-circulating system. For each species, one male was placed in a tank with 4-5

127 females to facilitate breeding and fish were fed 2x/day with commercial flake food. Fry were 128 extracted from the mouths of brooding females a few days after hatch and reared in small 
129 containers supplied with a constant flow of tank water and after yolk absorption were fed high-

130 quality Spirulina flake food (as per Albertson and Kocher, 2001). Fish were sampled periodically

131 over two months yielding developmental series that were prepared for histological analysis,

132 SEM, and clearing and staining (Fig. 1). All fish were anaesthetized in MS222 and fixed in 10\%

133 formalin in phosphate-buffered saline (PBS). All procedures followed an approved IACUC

134 protocol.

136 Histological Analysis

137 Histological material was prepared from one brood each of Labeotropheus $(\mathrm{n}=9,11-70 \mathrm{dpf}$, 138 7.5-21.5 mm SL), Metriaclima (n=9, 11-70 dpf, 8-23 mm SL), and Aulonocara $(\mathrm{n}=18,5-53 \mathrm{dpf}$, $139<5.0-23 \mathrm{~mm}$ SL; Fig. 1). Labeotropheus and Metriaclima $>11 \mathrm{~mm}$ SL were decalcified in Cal-Ex 140 (Fisher) for 4 hours (11-12 $\mathrm{mm} \mathrm{SL})$, or overnight ( $\geq 16 \mathrm{~mm} \mathrm{SL})$, then rinsed in phosphate buffer, 141 and placed for one hour each, in cold 5\%,10\% and 20\% sucrose solutions in PBS. Aulonocara 142 was decalcified for 2 hours (6.0-7.5 mm SL), 3.5 hours (8.0-8.5 mm SL) or 8 hours $(>8.5 \mathrm{~mm}$ 143 SL). All fish were dehydrated in an ascending ethanol and t-butyl alcohol series and embedded in 144 Paraplast Plus (Fisher). Serial transverse sections were cut at $8 \mu \mathrm{m}$, mounted on slides subbed 145 with $10 \%$ albumen in $0.9 \% \mathrm{NaCl}$, and stained with a modification of the HBQ stain (Hall, 1986) 146 to accomplish differential staining of cell nuclei, cartilage and bone. The supraorbital (SO), 147 mandibular (MD), preopercular (PO) and infraorbital (IO) canals were easily observed in 148 histological sections.

149 The supraorbital (SO) and mandibular (MD) canals run rostro-caudally in the nasal and 150 frontal bones (dorsal surface of skull) and in the dentary and anguloarticular bones (lower jaw) 151 were particularly conducive to quantitative analysis histological material (also see Tarby and 
For J.Morphol., February 8, 2014

152 Webb, 2003; Webb and Shirey, 2003). First, a complete inventory of serial transverse sections of

153 the head in each specimen revealed canal neuromast location, and names (SO1-5, MD1-5) were

154 assigned based on their location. Then, the pattern and timing of the development of the canal

155 segments forming around each canal neuromast were assessed using the developmental stages

156 defined for Amatitlania nigrofasciata (=Archocentrus nigrofasciatus, Stages I-IV; Tarby and

157 Webb, 2003).

158 A quantitative analysis of the rate of neuromast growth (length and width of SO1-5, MD1-5)

159 and increase in canal diameter (at the level of each canal neuromast) was carried out for the SO

160 and MD canals in larvae and juveniles $(5-25 \mathrm{~mm})$ of all three species. This allowed a test of the

161 hypothesis that heterochronic changes in the rates of increase in neuromast size (length, width)

162 and canal diameter among species can explain the evolution of a widened lateral line canal

163 system from a narrow lateral line canal system. In addition, a comparison of canal and

164 neuromast development in the SO and MD canals in the three species was used to determine if

165 there is evidence for regional (or local) heterochrony between the MD and SO canals. It was

166 predicted that the MD canal would be wider, which would be consistent with the notion that the

167 MD is an adaptation, in particular, for detection of benthic prey in Aulonocara (Schwalbe, et al.,

168 2012).

169 Neuromast length was determined by counting the number of sections in which neuromast

170 tissue (hair cells surrounded by thickened epithelium composed of mantle cells) was present and

171 multiplying by section thickness $(8 \mu \mathrm{m}$; measurement error $\pm 16 \mu \mathrm{m})$. Neuromast width was

172 measured (to nearest $0.1 \mu \mathrm{m}$ ) at the rostro-caudal midpoint of each canal neuromast by digitally

173 tracing the curve defined by the apical surface of the cells composing the neuromast around the

174 inner circumference of the canal. Internal canal diameter (defined by internal surface of ossified 
For J.Morphol., February 8, 2014

175 canal bone) was measured (to nearest $0.1 \mu \mathrm{m}$ ) at the level of each neuromast in the same section

176 as neuromast width, across the canal, at its widest point above the neuromast. Canal diameter

177 could not be measured until canal morphogenesis had commenced, so canal diameter was

178 determined only in those canal segments that were already at Stage II-IV. Canal diameter is

179 known to fluctuate such that canal diameter tends to be larger between neuromast positions than

180 at neuromast positions along the canal, especially in some (but not all) species with widened

181 canals (Webb, 2014). Thus, by measuring diameter at the level of each neuromast, comparisons

182 among species with narrow and widened canals are more consistent and provide a conservative

183 measure of interspecific differences in canal diameter.

184 All measurements were obtained digitally using Spot software (v. 5.0, Diagnostic

185 Instruments, Sterling Heights, MI USA) on an Olympus BH-2 or Zeiss AxioVision software (v

186 4.6.3, Carl Zeiss MicroImaging GmbH, Gottingen, Germany) on a Zeiss AxioImager1 compound

187 microscope. Left-right means of values for each parameter (canal diameter, neuromast length,

188 neuromast width) were calculated to reduce the effects of asymmetry arising with variation in

189 plane of section among individuals. Analysis of Covariance (ANCOVA; JMP, v.10.0.2, SAS

190 Institute, Inc.) was used to detect differences in slopes for each parameter (canal diameter,

191 neuromast length, neuromast width) among the three species after data were tested for normality,

192 and $\log$ transformed if needed. If slopes for a given parameter were determined to be

193 heterogeneous (statistically different), then the Johnson-Neyman technique (Johnson and

194 Neyman, 1936) was performed to determine the range of $X$ values (in this case, fish size) in

195 which there is no significant difference in the parameter of interest ("region of non-significance";

196 White, 2003) between two species and by extension, the range of fish sizes in which a significant

197 difference is present. A similar analysis was then performed to detect differences ontogenetic 
For J. Morphol., February 8, 2014

198 trends in neuromast size (length, width) and canal diameter in the SO versus MD canals in each

199 of the three study species using the same approach. Significance was defined a priori as $P<0.05$

200 in all analyses. The graphic representation of data is derived from raw (not log transformed data)

201 to illustrate biologically (as opposed to statistically) relevant measurements.

202

203 Scanning Electron Microscopy

204 Specimens of Labeotropheus (from two broods including that used for histological analysis,

205 7-70 dpf, 7.5-26 mm SL, n=17; Fig. 1) were dehydrated in an ascending series of ethanol, critical 206 point dried in liquid $\mathrm{CO}_{2}$, coated with Au-Pd alloy, and mounted on carbon-coated stubs in order

207 to visualize as many of the lateral line canals as possible. Specimens were imaged with a Hitachi 208 S5-7 SEM and acquired using 4x5 Polaroid film. Photos were scanned at high resolution and 209 minimally post-processed using Adobe Photoshop 4.0 (Adobe Systems, Inc., San Jose, CA, 210 USA).

\section{Clearing and Staining and $\boldsymbol{\mu}$ CT Imaging}

213 Aulonocara baenschi (12-39 dpf, 7-19 mm SL, n=12, from one brood; Fig. 1) were

214 enzymatically cleared and stained for both bone (Alizarin Red) and cartilage (Alcian Blue;

215 Potthoff, 1984) to visualize the lateral line canals. In addition, micro-computed tomographic $216(\mu \mathrm{CT})$ imaging was carried out on a formalin-fixed specimen of Aulonocara baenschi $(87 \mathrm{~mm}$

217 SL). The fish was imaged in air using tube settings of $45 \mathrm{kVp}$ and $177 \mu \mathrm{A}$, integration time of $218300 \mathrm{~ms}$, and scan resolution (voxel size) of $6 \mu \mathrm{m}$ (smaller fish) or $16 \mu \mathrm{m}$ (larger fish) using a $219 \mu \mathrm{CT} 40$ (Scanco Medical AG, Brütisellen, CH). Once reconstructed, 3-D image volumes were 
For J. Morphol., February 8, 2014

220 exported as DICOM image stacks and reconstructed using volume and surface rendering

221 protocols in OsiriX (Pixmeo, Geneva Switzerland; http://www.osirix-viewer.com/).

222

\section{RESULTS}

224 The timing of major developmental events was similar in all three species. Hatching occured 225 at $<7$ days post-fertilization ( $\mathrm{dpf}$, at $<5 \mathrm{~mm} \mathrm{TL}$ ) and newly hatched fry had a large ovoid yolk sac

226 (Fig. 2). Caudal fin flexion started quickly, just a few days post-hatch, and was complete at 7-8

227 dpf ( $<7.5 \mathrm{~mm} \mathrm{SL})$ in Labeotropheus and Metriaclima and a few days later in Aulonocara (11

$228 \mathrm{dpf}, \sim 7 \mathrm{~mm} \mathrm{SL}$ ). In all three species, the yolk sac was not absorbed until well after flexion was

229 complete, at 18-21 dpf (11-12 mm SL; Balon, 1977; C. Albertson, pers. comm.), just prior to the

230 normal time of release from the mother's mouth.

231

232 Distribution of Canals and Canal Neuromasts

233 Labeotropheus, Metriaclima and Aulonocara have the same number of canal neuromasts and

234 the same complement of cranial lateral line canals. Five canal neuromasts are present in the

235 supraorbital canal (SO1-5). SO1 is located in the portion of the canal in the tubular nasal bone

236 just medial to the naris (Fig. 4C, 5A, C) and neuromasts SO2-5 are located in the portion of the

237 canal embedded in the frontal bone. Five canal neuromasts (MD1-5) are present in the

238 mandibular canal (Fig. 3A-C). Neuromasts MD1-4 are in the portion of the MD canal in the

239 dentary bone, and neuromast MD5 is located in the short canal segment in the angulo-articular

240 bone (Fig. 3A-C, and in illustrations of Labeotropheus and Metriaclima in Albertson and Kocher

241 (2001). In addition, the preopercular (PO) canal, which is contiguous with the MD canal, is

242 contained in the L-shaped preopercular bone (Fig. 3A-C; Fig. 4A, B). The infraorbital (IO) canal 
For J. Morphol., February 8, 2014

243 is contained within the lacrimal bone just under the rostro-ventral border of the orbit (Fig. 4C)

244 and continues caudally in the series of infraorbital ossicles that follow the circumference of the

245 orbit (Fig. 3A-C). The difference in the diameter of the IO canal in Labeotropheus and

246 Metriaclima (Fig. 3A, B) versus Aulonocara (Fig. 3C). is particularly noticeable. On the dorsal

247 surface of the head, the pore between neuromasts $\mathrm{SO} 3$ and SO 4 in each of the SO canals extend

248 medially to form a pore in the dorsal midline, joining the right and left SO canals (Fig. 5C, D).

249 Finally, caudal to the orbit the post-otic canal continues through the pterotic, extrascapular, post-

250 temporal, and supracleithral bones and is contiguous with the trunk canal contained in the lateral

251 line scales.

252

\section{Pattern and Timing of Canal Morphogenesis}

254 In all three species, the pattern of development of individual canal segments was the same

255 (e.g., Stages I-IV; Tarby and Webb, 2003) despite differences in canal morphology (narrow vs.

256 widened). Initiation of canal morphogenesis, marked by the formation of longitudinal

257 depressions or grooves in the vicinity of individual canal neuromasts (Stage II; Fig. 6B, C, G, H),

258 started within two weeks of fertilization (at 7-8 $\mathrm{mm} \mathrm{SL}$ ). The processes of canal segment

259 enclosure (Stage III; Fig. 6D, I) and ossification (Stage IV; Fig. 6E, J) then continued for many

260 more weeks through metamorphosis (larval-to-juvenile transformation; at 10-12 mm SL), and a

261 concurrent three-fold increase in fish size.

262 A comparison of the timing of canal morphogenesis showed considerable asynchrony among

263 canals. In Labeotropheus, SO, MD, and PO canal grooves (Stage II) were visible as early as $\sim 10$ -

$26411 \mathrm{dpf}$ (7-8 mm SL; Fig. 4A, C). Within a day (at $12 \mathrm{dpf}$ ), the SO and MD canals started to

265 enclose (Stage III). Several days later (17-18 dpf, 11-12 mm SL), the PO and MD canals were 
266 partially or completely enclosed, and the infraorbital (IO) canal (the portion in the lacrimal bone,

267 but not the remainder of the IO canal contained within in the infraorbital ossicles) was enclosed

268 (Fig. 4C, D). Within two days (19-20 dpf, $12 \mathrm{~mm} \mathrm{SL}$, when fish are normally ready to be

269 released from the mother's mouth), some or all of the segments that compose each of the canals,

270 with the exception of the portion of the IO canal in the infraorbital ossicles caudal to the lacrimal

271 bone, had enclosed and ossification (Stage IV) had started (Fig. 5A, B). After several weeks (by

$27242 \mathrm{dpf}, 16 \mathrm{~mm} \mathrm{SL}$ ), the SO, MD and PO canals had all ossified (Stage IV), and the IO canal

273 segments in the infraorbital ossicles were finally enclosed (Stage III). SEM illustrated the pores

274 in one juvenile at $56 \mathrm{dpf}(\sim 19 \mathrm{~mm} \mathrm{SL})$ in which the pores of adjacent canal segments that

275 compose the IO canal had still not fused, leaving double pores (Fig. 5E) and at $70 \mathrm{dpf}(\sim 23 \mathrm{~mm}$

276 SL) the double pores had fused to form the single pores characteristic of adult fishes (Fig. 5F).

277 The timing of canal morphogenesis in Metriaclima appears to be similar to that in

278 Labeotropheus. The SO, MD and PO grooves (Stage II) were apparent in young larvae just after

279 flexion was complete ( $11 \mathrm{dpf}, 7-8 \mathrm{~mm} \mathrm{SL})$, and most or all of the SO and MD canal segments

280 were enclosed (Stage III) about a week later (17-20 dpf; $11 \mathrm{~mm}$ SL). By 20-22 dpf (11-12 mm

281 SL), the portion of the IO canal in the lacrimal (containing three canal neuromasts) was enclosed,

282 but the enclosure of the remainder of the IO canal (in the infraorbital ossicles) was delayed for

283 many weeks (Fig. 4C, 6E, F). The SO and MD canal segments were all ossified (Stage IV) in

284 juveniles between 42 and $56 \mathrm{dpf}(\sim 19-20 \mathrm{~mm} \mathrm{SL})$.

285 In Aulonocara, SO grooves (Stage II) were present a bit earlier (at $8 \mathrm{dpf}, \sim 5 \mathrm{~mm}$ SL) and

286 some MD grooves were already present at $11 \mathrm{dpf}(\sim 7 \mathrm{~mm} \mathrm{SL})$ as in Labeotropheus and

287 Metriaclima. Enclosure of the SO and MD canals (Stage III) started in slightly older individuals

288 (15-17 dpf, 9-11 mm SL) than in Labeotropheus and Metriaclima, as yolk absorption had begun. 
For J.Morphol., February 8, 2014

At 20-26 dpf (11-12 mm SL), the SO and MD canals, and the portion of the IO canal in the lacrimal bone were enclosed and had begun to ossify (Stage IV); the SO and MD canals were ossified several weeks later (47 dpf; 21-22 mm SL).

The onset of canal enclosure (Stage III) and canal ossification (Stage IV) in the SO and MD canals showed some interesting contrasts between the species with narrow canals (Labeotropheus and Metriaclima) and widened canals (Aulonocara). First enclosure in the SO canal occurred by 11-12 dpf in Labeotropheus and Metriaclima, but occurred over a longer interval (11 to $15 \mathrm{dpf}$ ) in Aulonocara. First ossification in the SO canal occurred between 12 and $17 \mathrm{dpf}$ in Labeotropheus and Metriaclima, and a few days later (17 to $20 \mathrm{dpf}$ ) in Aulonocara. Similarly, first enclosure in the MD canal occurred by 11-12 dpf in Labeotropheus and Metriaclima, and a few days later (15 to $17 \mathrm{dpf}$ ) in Aulonocara. First ossification in the MD canal occured at 12 to $17 \mathrm{dpf}$ in Labeotropheus and Metriaclima, but several days later (23 to 26 dpf) in Aulonocara.

\section{Order and Timing of Development of Segments within Canals}

Asynchrony in development was obvious among canal segments within a canal, but a particular canal segment was not observed at all four of the developmental stages (I-IV) in different individuals due to the rapid progression of canal development and the size and age of individuals available for analysis. Thus, mean fish size at first canal enclosure (Stage III) and canal ossification (Stage IV) for each canal segment was used to approximate the relative order and timing of the development of canal segments within the SO and MD canals (Table 1).

The development of the segments of the SO and MD canals did not occur in a simple rostrocaudal (or caudo-rostral) direction within a canal. Nevertheless, a consideration of the mean fish 
For J.Morphol., February 8, 2014

312 size at which a particular canal segment enclosed and ossified among the individuals analyzed

313 revealed trends that allowed some generalizations to be made (see Table 1). In the SO canal, the

314 SO4 canal segment appeared to be the first to enclose (at $\sim 8-9 \mathrm{~mm}$ SL) and the first to ossify in

315 all three species. The other segments then enclosed in a roughly caudal to rostral direction, with

316 the more caudal segments (SO3-5) tending to enclose before the more rostral segments (SO1-3).

317 Subsequent ossification occurred in roughly the same order among segments. The order and

318 timing of the enclosure and ossification of individual canal segments appears to be a bit different

319 in the MD canal. The MD2 segment tended to enclose first in Labeotropheus, but the MD3

320 segment tended to enclose first in Metriaclima and Aulonocara. The order of ossification did not

321 reveal any particular pattern in Labeotropheus, but in Metriaclima and Aulonocara, the more

322 caudal segments (MD3-5) enclosed before the more rostral segments (MD1-2).

\section{Canal Diameter at Enclosure and Ossification}

325 Canal diameter could be measured as soon as a neuromast had sunk into a depression or

326 groove (Stage II, Fig. 6B, G). Canal diameter continued to increase as bone ossified to form the

327 canal walls (Fig. 6C, H), as the canal enclosed (Stage III, Fig. 6D, I), and as the canal roof

328 ossified (Stage IV; Fig. 6E, J). The minimum canal diameters for each SO and MD canal

329 segment at first enclosure (Stage III) and ossification (Stage IV) provided insights into the

330 functional implications of canal growth during larval and juvenile development (Table 1). In

331 Labeotropheus and Metriaclima (narrow canals) the SO and MD canal segments were first

332 enclosed at diameters of at least $\sim 65$ and $\sim 95 \mu \mathrm{m}$, respectively, but in Aulonocara (widened

333 canals) they enclosed at diameters of at least $\sim 70$ and $\sim 115 \mu \mathrm{m}$, respectively. Thus, the MD

334 canal segments tended to enclose at larger diameters than those of the SO canal in all three 
For J. Morphol., February 8, 2014

335 species and the MD canal in Aulonocara tended to enclose at larger diameters than in either

336 Labeotropheus or Metriaclima. Ossification occurred at diameters of at least $20 \mu \mathrm{m}$, but in some

337 cases, $60 \mu \mathrm{m}$ greater than the diameters at which enclosure was observed in a particular MD

338 canal segment. The minimum diameter at which the five MD segments ossified was 83-109 $\mu \mathrm{m}$

339 in Labeotropheus (versus 78-120 $\mu \mathrm{m}$ for its five SO segments), 108-170 $\mu \mathrm{m}$ in Metriaclima

340 (versus 81-119 $\mu \mathrm{m}$ for its SO segments) and 136-194 $\mu \mathrm{m}$ in Aulonocara (versus 93-183 $\mu \mathrm{m}$ for

341 its SO segments).

343 Quantitative Analysis of Neuromast and Canal Development

344 An ANCOVA (SO and MD canal data combined) revealed that rates of increase in canal

345 diameter and neuromast size (length, width) varied significantly among species (Fig. 7, Table 2).

346 However, significant interactions (species x fish size) were found for neuromast size (length and

347 width) and canal diameter, so the Johnson-Neyman technique (White, 2003) was used to

348 determine the range of fish sizes in which each parameter was not statistically different (between

349 species pairs), and thus by extension when it was statistically different $(P<0.05)$.

350 The ontogenetic rate of increase in canal diameter was not statistically different (equal

351 slopes) in Labeotropheus and Metriaclima, but canal diameters were consistently larger in

352 Metriaclima (Table 2). The rate of increase in canal diameter in Aulonocara was 1.5 and 1.9

353 times that in Labeotropheus or Metriaclima, respectively (Fig. 7A; Table 2, 3). As a result, canal

354 diameter was already significantly larger in Aulonocara than in either Labeotropheus or

355 Metriaclima larvae at lengths $>4.5$ and $>7.8 \mathrm{~mm}$ SL, respectively.

356 Similarly, the ontogenetic rate of increase in neuromast length was not statistically different

357 in Labeotropheus and Metriaclima, but neuromasts were consistently longer in Labeotropheus 
For J.Morphol., February 8, 2014

358 than in Metriaclima (Fig. 7B; Table 2, 3). In Aulonocara, neuromast length increased at a rate

359 that was 2.7 or 2.8 times that in Labeotropheus or Metriaclima, respectively (Table 3) and

360 neuromast length was significantly greater in Aulonocara than in either Labeotropheus or

361 Metriaclima larvae at lengths $>12.3$ and $>9.0 \mathrm{~mm} \mathrm{SL}$, respectively. The ontogenetic rate of

362 increase in neuromast width was not statistically different in Labeotropheus and Metriaclima,

363 but neuromast width was consistently greater in Metriaclima (Fig. 7C). Neuromast width in

364 Aulonocara increased at a rate 2.2 or 1.6 times that in Labeotropheus or Metriaclima,

365 respectively (Table 2) and was significantly greater in Aulonocara larvae than in either

366 Labeotropheus or Metriaclima larvae at lengths $>8.3$ and $>7.6 \mathrm{~mm}$ SL, respectively.

367 Another ANCOVA revealed differences in rates of increase in canal diameter and neuromast

368 size (length, width) in the supraorbital (SO) versus the mandibular (MD) canal in the three study

369 species (Table 4, 5). In Labeotropheus, canal diameter and neuromast length increased at rates

370 that were not statistically different in the SO and MD canals, but SO canals were wider and SO

371 neuromasts were longer than the MD canal and MD canal neuromasts (Table 4). The rate of

372 increase in neuromast width was 1.8 times greater in the SO canal than in the MD canal (Table

373 5), such that neuromasts were significantly wider in the SO canal than in the MD canal in larvae

$374>9.7 \mathrm{~mm}$ SL. In Metriaclima, neuromast length in the two canals increased at rates that were not

375 statistically different (Table 4), but neuromasts were consistently longer in the SO canal. The

376 rates of increase of neuromast width and canal diameter were greater in the SO canal in

377 Metriaclima by a factor of 2.1 and 1.6, respectively (Table 5), such that SO neuromast width was

378 significantly greater in larvae $>16.0 \mathrm{~mm}$ SL, and SO canal diameter was significantly greater in

379 larvae $>14.1 \mathrm{~mm}$ SL. In Aulonocara, canal diameter and both neuromast length and width all

380 increase faster in the SO canal than in the MD canal (Table 4), which was unexpected. Canal 
381 diameter increased 1.3 times faster in the SO canal than in the MD canal (Table 5), such that the

382 SO canal was significantly wider than the MD canal in larvae $>15.2 \mathrm{~mm}$ SL. Neuromast length

383 and width both increased 1.2 times faster in the SO canal (Table 5) such that SO neuromasts

384 were significantly longer and wider than MD neuromasts in larvae at lengths $>12.3 \mathrm{~mm}$ SL and

$385>9.6 \mathrm{~mm} \mathrm{SL}$, respectively. The differences in developmental rate between the SO and MD canal 386 can be attributed to regional (local) heterochrony.

\section{DISCUSSION}

389 This study has provided the first detailed description of the development of widened lateral

390 line canals in a teleost, and the first detailed comparison of the development of narrow and

391 widened canals. It has shown that: 1) canal neuromast number and the pattern of canal

392 morphogenesis are conserved, regardless of adult canal morphology, 2) the evolution of widened

393 canals from narrow canals can occur via dissociated heterochrony (a combination of peramorphic

394 and paedomorphic trends) and regional (local) heterochrony in canal diameter and neuromast

395 size between canals accounts for variation among canals within a species, and 3) the morphology

396 of the lateral line canals and the dermal bones in which they are found (e.g., the mandibular canal

397 contained within the dentary and anguloarticular bones of the mandible) can evolve

398 independently of each other.

\section{Pattern and timing of development in narrow versus widened canals}

401 The three study species (Labeotropheus fuelleborni, Metriaclima zebra, Aulonocara

402 baenschi) had the same complement of canal neuromasts in the SO and MD canals. This is

403 evidence of a conserved process of neuromast patterning that is independent of the subsequent 
For J.Morphol., February 8, 2014

404 development of the lateral line canals. In addition, the same pattern of development was

405 observed in the three study species and occurs in four stages as described in a South American

406 cichlid with narrow canals (Amatitlania nigrofasciata = Archocentrus nigrofasciatus; Tarby and

407 Webb, 2003), and an unrelated teleost, the zebrafish, Danio rerio (Webb and Shirey, 2003).

408 Thus, the pattern of groove formation (Stage II), enclosure (Stage III) and canal roof ossification

409 (Stage IV) that results in the formation of lateral line canal segments appears to be conserved

410 among teleosts with both narrow and widened canals.

411 The timing of the different stages of canal development varies among species (Tarby and

412 Webb, 2003; Webb and Shirey, 2003) and may be related to functional demands in developing

413 fishes (Webb, 2013). For instance, the morphogenesis of the cranial lateral line canals progresses

414 quickly to Stage IV (ossification of enclosed canal segments) in both the African cichlids

415 examined in this study and the South American convict cichlid examined in a prior study

416 (Amatitlania nigrofasciata; Tarby and Webb, 2003). The result is that in Labeotropheus,

417 Metriaclima and Aulonocara, canal enclosure (Stage III) and ossification (Stage IV) is well-

418 underway after a prolonged process of yolk absorption when transforming juveniles are normally

419 released from the mother's mouth, and must start to feed (at $\sim 21$ days post-fertilization). In

420 contrast, the cranial lateral line canals in larval and juvenile zebrafish demonstrates a prolonged

421 stage II, in which presumptive canal neuromasts sit in open grooves (Webb and Shirey, 2003).

422 This morphology is predicted to facilitate detection of prey at the water's surface in their native

423 habitat, as has been demonstrated in killifish (Schwarz, et al., 2011).

424 The quantitative ontogenetic analysis presented here has demonstrated that canal diameter

425 and neuromast size are initially similar among the three study species, but that significantly

426 different rates of increase in these parameters result in the development of narrow canals 
For J.Morphol., February 8, 2014

427 (Labeotropheus and Metriaclima) versus widened canals (Aulonocara). In addition, the process

428 of canal enclosure in the SO and MD canals commences a bit later and the process is a bit more

429 prolonged (over a longer growth interval) and occurs at larger canal diameters in Aulonocara in

430 contrast to the narrow canals of Labeotropheus and Metriaclima. Nevertheless, by the time

431 larvae are normally released from the mother's mouth ( $21 \mathrm{dpf} ; 11-12 \mathrm{~mm} \mathrm{SL})$, canal diameter

432 (Fig. 4e, j) and neuromast length and width already distinguish Aulonocara (widened canals)

433 from Labeotropheus and Metriaclima (narrow canals).

434 Interspecific differences in lateral line morphology are correlated with differences in feeding

435 habit. Labeotropheus feeds on filamentous algae from rocks and Metriaclima brushes loose

436 plant matter from algae beds, but also plucks plankton from the water column (Albertson and

437 Kocher, 2006), and it is likely that the lateral line system is not critical for feeding in these taxa.

438 However, Aulonocara stuartgranti uses its widened lateral line canal system to detect benthic

439 invertebrate prey as it swims and glides over sandy substrates (Schwalbe et al., 2012). Its

440 feeding behavior suggests that the MD canal, lower arm of the PO canal, and perhaps the portion

441 of the IO canal ventral to the orbit (whose pores are obvious in ventral view, Fig. 3) are critical

442 for prey detection. Surprisingly, the SO canal increases in diameter faster than the MD canal

443 such that the SO canal is wider in diameter and its canal neuromasts are longer and wider than

444 those in the MD canal in all three study species, regardless of canal morphology. Thus, the

445 prediction that canal diameter and neuromast size in the MD canal would be greater than in the

446 SO canal as the result of adaptive function for benthic prey detection was not borne out.

447 Nevertheless, in Aulonocara, the MD canal enclosed and was ossified at diameters $>100 \mu \mathrm{m}$ and

448 canal diameter and was already larger than in Labeotropheus or Metriaclima in early larvae

449 (lengths $>7.8 \mathrm{~mm}$ SL), such that the widened MD canal becomes morphologically 
For J. Morphol., February 8, 2014

450 distinguishable from the narrow MD canal well before feeding commences. The timing of the

451 onset of lateral line-mediated feeding behavior (as described in adults, Schwalbe et al., 2012) is

452 not yet known, but it is predicted that it will be dependent on the development of their typical

453 prey search strategy (three phase cycle: swim, glide, pause) as well as favorable hydrodynamic

454 properties of the lateral line canals that will allow stimulation of canal neuromasts by the water

455 flows generated by prey.

456 It is concluded that the evolution of widened canals and their larger canal neuromasts are the

457 result of dissociated heterochrony. High rates of increase in canal diameter and neuromast size

458 are interpreted as peramorphic trends and the delay of SO and MD canal enclosure and the

459 prolonged duration of this process in Aulonocara in contrast to Labeotropheus and Metriaclima

460 are interpreted to be paedomorphic trends. In addition, the initial process of canal roof

461 ossification and fusion of adjacent canal segments to form a common pore is followed by a

462 decrease in pore size in Labeotropheus (Fig. 5C, D and Fig. 5E, F), a process noted by Allis

463 (1889) in Amia calva. Thus, the evolution of large canal pores characteristic of widened canals

464 (Webb, 1989b) appears to be the result of a paedomorphic trend - either a slower rate in, or

465 truncation of the process of ossification of the canal roof in comparison to that in species with

466 well-ossified narrow canals that have smaller canal pores.

467

468 The Mandibular Lateral Line Canal as a Component of the Mandible

469 Labeotropheus and Metriaclima are distinguished by the morphology and genetics of the oral

470 jaw apparatus, including differences in the length and width of the lower jaw (Albertson and

471 Kocher, 2006), which are attributed to directional selection (Albertson, et al., 2003). A QTL

472 analysis had indicated that several aspects of mandibular morphology critical for feeding are 
For J.Morphol., February 8, 2014

473 inherited as modules, thus supporting the notion of a degree of morphological integration in the

474 cichlid mandible (Albertson and Kocher, 2006). However, the function of the mandible is not

475 limited to feeding and it is thus subjected to other selective pressures, such as those associated

476 with lateral line function. This study has shown that the diameter of the MD canal and size of the

477 canal neuromasts contained within it are not significantly different in Labeotropheus and

478 Metriaclima in mid-stage larvae and older or larger individuals, despite significant differences in

479 overall mandibular morphology (Konings, 1990). The mandibular canal is narrow and well-

480 ossified in both species, with the same number of canal neuromasts and small canal pores.

481 Interestingly, the canal pores in the shortened mandible of Labeotropheus appear to be more

482 closely positioned to each other than those in Metriaclima (as in Fig. 3 and illustrations in

483 Albertson and Kocher, 2001). This difference in inter-pore distance, presumably related to

484 differences in mandibular length, may have unappreciated consequences for the lateral line

485 function (discussed in Coombs and van Netten, 2006).

486 If the mandible can respond to directional selection with respect to feeding while the MD

487 canal does not change in diameter, then it follows that the morphology of the MD canal could

488 evolve independently of lower jaw morphology in response to selection for modified water flow

489 detection. For example, the morphology of the lower jaw of Aulonocara spp. (Fig. 3a, b) appears

490 to be similar to that in Metriaclima, but this study has shown that while neuromast patterning

491 (number of canal neuromasts) does not differ between these two taxa, canal width and neuromast

492 size diverge in larval Aulonocara and Metriaclima, to become the widened and narrow lateral

493 line canals characteristic of juveniles and adults (Fig. 6E, J). The evolution of widened canals

494 from narrow canals for the enhancement of prey detection capabilities may also have impacts on

495 lower jaw function. Examination of dried skeletons revealed that the mandible of Aulonocara 
For J. Morphol., February 8, 2014

496 appears particularly "delicate" (Webb and Kocher, unpubl. observ.) due to reduced ossification

497 of the canal roof resulting in their characteristically large pores, but the consequences of these

498 features for feeding mechanics have not been considered. A consideration of the lateral line

499 canals as components of the dermatocranial bones, with functional roles (e.g., ventrally directed

500 canals in benthic feeders) or more subtle architectural or constructional roles (e.g., the dorsal SO

501 canal in the frontal bone), is an aspect of the analysis of the integration and modularity in the

502 skull of fishes that deserves more attention.

503

504 Summary

505 This study has demonstrated that simple, correlated changes in developmental rates

506 (heterochrony) in the lateral line canals contained within dermal bones (a component of the

507 dermatocranium) and in canal neuromasts (a component of the peripheral nervous system) can

508 explain the evolution of an adaptive phenotype, widened lateral line canals. In particular, it

509 revealed "dissociated heterochrony" among species with narrow vs. widened canals (a

510 combination of peramorphic and paedomorphic shifts), as well as regional (local) heterochrony,

511 differences in rates between canals (and between their respective neuromasts) within individuals.

512 The genetic basis of these changes deserve further study and will need to consider the processes

513 of intramembranous bone ossification and dynamics of hair cell populations in neuromasts. This

514 study also demonstrated that heterochronic change in canal diameter and neuromast morphology

515 can occur without a change in other aspects of lateral line development (e.g., neuromast

516 patterning [canal neuromast number] or the pattern/process of neuromast-centered canal

517 morphogenesis). With reference to the life history of the mouth brooding cichlid fishes used in

518 this study, the divergence in canal phenotype (narrow vs. widened) has already occurred in 
For J.Morphol., February 8, 2014

519 young larvae, so that by the time they are released from the mother's mouth and exogenous

520 feeding commences, canal diameter and neuromast size already distinguish Aulonocara

521 (widened canals) from Labeotropheus and Metriaclima (narrow canals), which is likely to have

522 interesting implication for the ontogeny of prey detection capabilities. Finally, the ability of the

523 lower jaw to evolve independently of lateral line canal morphology (Labeotropheus vs.

524 Metriaclima), and the ability of the lateral line canals (and neuromasts) to evolve independently

525 of the lower jaw (Aulonocara vs. Metriaclima), demand that the canals of the mechanosensory

526 lateral line system become a part of the conversation concerning integration and modularity in

527 the skull of fishes.

529 ACKNOWLEDGMENTS

530 We thank Thomas Kocher, Karen Carleton and Craig Albertson for providing the specimens

531 used in this study. Morgan Falk did a portion of the initial histological analysis as part of her

532 Senior Honors Thesis at Villanova University. Douglas Moore (Orthopedics Research Lab, RI

533 Hospital/Brown Medical School) carried out $\mu$ CT scans and Timothy Alberg generated 3-D

534 images from $\mu \mathrm{CT}$ data. Jason Kolbe provided statistical expertise. The initial preparation of

535 histological and SEM material was supported by an NSF Research Opportunity Award to JFW as

536 a supplement to NSF grant DEB-9905127 to Thomas Kocher. Completion of this work was

537 supported by the College of the Environment and Life Sciences, University of Rhode Island and

$538 \quad$ NSF Grant No. 0843307 to JFW.

\section{LITERATURE CITED}

541 Albertson RC, and Kocher TD. 2001. Assessing morphological differences in an adaptive trait: A 
542 landmark-based morphometric approach. J Exper Zool 289:385-403.

543 Albertson RC, and Kocher TD. 2006. Genetic and developmental basis of cichlid trophic

544 diversity. Heredity 97:211-21.

545 Albertson RC, Streelman JT, and Kocher TD. 2003. Genetic basis of adaptive shape differences

$546 \quad$ in the cichlid head. J Heredity 94:291-301.

547 Allis EP. 1889. The anatomy and development of the lateral line system in Amia calva. J

$548 \quad$ Morphol 2:463-542+ plates.

549 Aman A, and Piotrowski T. 2011. Cell-cell signaling interactions coordinate multiple cell

550 behaviors that drive morphogenesis of the lateral line. Cell Adh Migr 5:499-508.

551 Balon EK. 1977. Early ontogeny of Labeotropheus Ahl, 1927 (Mbuna, Cichlidae, Lake

552 Malawi), with a discussion of advanced protective styles in fish reproduction and

553 development. Env Biol Fishes 2:147-176.

554 Branson BA. 1961. The lateral-line system in the Rio Grande Perch, Cichlasoma cynoguttatum 555 (Baird and Girard). Amer Midl Nat 65:446-458.

556 Chitnis AJ, Nogare DD, and Matsuda M. 2011. Building the posterior lateral line system in $557 \quad$ zebrafish. Devel Neurobiol 72:234-255.

558 Coombs S and Van Netten S. 2006. The hydrodynamics and structural mechanics of the lateral

559 line system. In: Shadwick RE and Lauder GV editors, Fish Biomechanics, San Diego:

$560 \quad$ Elsevier Academic Press. pp. 103-139.

561 Denton EJ and Gray JAB. 1988. Mechanical factors in the excitation of the lateral lines of fish.

562 In: Atema J, Fay RR, Popper AN, and Tavolga WN, editors. Sensory Biology of Aquatic

563 Animals. New York: Springer-Verlag. pp. 595-617. 
For J. Morphol., February 8, 2014

564 Denton EJ and Gray JAB. 1989. Some observations on the forces acting on neuromasts in fish

565 lateral line canals. In: Coombs, S, Görner P, and Munz H, editors. The Mechanosensory

566 Lateral Line: Neurobiology and Evolution. New York: Springer-Verlag. pp. 229-246.

567 Hall BK. The role of movement and tissue interactions in the development and growth of bone

568 and secondary cartilage in the clavicle of the embryonic chick. J Emb Exper Morphol

$569 \quad 93: 133-152$.

570 Hulsey D, Fraser GJ, and Streelman JT. 2005. Evolution and development of complex

571 biomechanical systems: 300 million years of fish jaws. Zebrafish 2:243-257.

572 Johnson PO and Neyman J. 1936. Tests of certain linear hypotheses and their application to

$573 \quad$ some educational problems. Stat Res Mem 1:57-93.

574 Konings A. 1990. Ad Koning's Book of Cichilds and Other Fishes of Lake Malawi. Neptune

575 City, NJ: TFH Publications.

576 Konings A. 2007. Malawi Cichlids in Their Natural Habitat, 4th ed. El Paso, Texas: Cichlid $577 \quad$ Press.

578 McNamara KJ. 1997. Shapes of Time - The Evolution of Growth and Development. Baltimore:

579 The Johns Hopkins University Press.

580 Meyer MK, Riehl R, and Zetzsche H. 1987. A revision of the cichlid fishes of the genus

581 Aulonocara Regan, 1922 from Lake Malawi, with descriptions of six new species (Pisces,

582 Perciformes, Cichlidae). Cour Forsch-Inst Senckenberg 94:7-53.

583 Moore ME, and Webb JF. 2008. Dermal bone remodeling in the cranial lateral line canals of

584 zebrafish: The role of osteoclasts. Integr Comp Biol 47:e142. 
For J. Morphol., February 8, 2014

585 Nuñez, BA, Sarrazin AF, Cubedo N, Allende ML, Dambly-Chaudière C, and Ghysen A. 2009.

586 Postembryonic development of the posterior lateral line in the zebrafish. Evol Devel

$587 \quad 11: 391-404$.

588 Peters HM. 1973. Anatomie und Entwicklungsgeschichte des Laterallissystems von Tilapia

589 (Pisces, Cichlidae). Z Morph Tiere 74:89-161.

590 Potthoff T. 1984. Clearing and staining technique. In: Moser, JG, editor-in-chief. Ontogeny and

591 Systematics of Fishes. Special Publication No. 1. Lawrence, Kansas: American Society of

592 Ichthyologists and Herpetologists. pp. 35-37.

593 Schwalbe MAB, Bassett DK, and Webb JF. 2012. Feeding in the dark: Lateral line mediated

594 feeding behavior in the peacock cichlid, Aulonocara stuartgranti. J Exp Biol 215:2060-

5952071.

596 Schwarz JS, Reichenbach T, Hudspeth AJ. 2011. A hydrodynamic sensory antenna used by

$597 \quad$ killifish for nocturnal hunting. J Exper Biol 214:1857-1866.

598 Streelman JT, Webb JF, Albertson RC and Kocher TC. 2003. The cusp of evolution and

599 development: a model of cichlid tooth shape diversity. Evol Devel 5:600-608.

600 Sylvester JB, Rich CA, Loh Y-HE, van Staaden MJ, Fraser GJ and Streelman JT. 2010. Brain

601 diversity evolves via differences in patterning. Proc Nat Acad Sci US 107:9718-9723.

602 Tarby ML and Webb JF. 2003. Development of the supraorbital and mandibular lateral line

603 canals in the cichlid, Archocentrus nigrofasciatus. J Morphol 255:44-57.

604 Webb, JF. 1989a. Developmental constraints and evolution of the lateral line system in teleost

605 fishes. In: Coombs, S, Görner P, and Munz H, editors. The Mechanosensory Lateral Line:

606 Neurobiology and Evolution. New York: Springer-Verlag. pp. 79-98. 
607 Webb JF. 1989b. Gross morphology and evolution of the mechanosensory lateral line system in 608 teleost fishes. Brain Behav Evol 33:34-53.

609 Webb JF. 1989c. Neuromast morphology and lateral line trunk ontogeny in two species of 610 cichlids: an SEM study. J Morphol 202:53-68.

611 Webb JF. 1990. Ontogeny and phylogeny of the trunk lateral line system in cichlid fishes. J Zool, $612 \quad$ London 221:405-418.

613 Webb JF. 2014. Morphological diversity, development, and evolution of the mechanosensory

614 lateral line system. In: Coombs S and Bleckmann, H, editors. The Lateral Line. New York:

615 Springer-Verlag. pp. 17-72.

616 Webb JF and Northcutt RG. 1997. Morphology and distribution of pit organs and canal

617 neuromasts in non-teleost bony fishes. Brain Behav Evol 50:139-151.

618 Webb JF and Shirey JE. 2003. Post-embryonic development of the lateral line canals and 619 neuromasts in the zebrafish. Devel Dynam 228:370-385.

620 Webb JF, Montgomery J, and Mogdans, J. 2008. Mechanosensory lateral line and fish

621 bioacoustics. In: Webb JF, Fay RR, Popper AN, editors. Fish Bioacoustics. New York:

$622 \quad$ Springer-Verlag. pp. 145-182.

623 White CR. 2003. Allometric analysis beyond heterogeneous regression slopes: Use of the 624 Johnson-Neyman technique in comparative biology. Physiol Biochem Zool 76:135-140. 
For J. Morphol., February 8, 2014

\section{Figure Captions}

629 Fig. 1. Fish age and size for specimens of Labeotropheus fuelleborni $(\mathrm{n}=25)$, Metriaclima

$630 z e b r a(\mathrm{n}=8)$, and Aulonocara baenschi $(\mathrm{n}=57)$ used for histological analysis, and for SEM and

631 clearing and staining, as noted.

632

633 Fig. 2. Larval and juvenile Aulonocara baenschi. A: Yolk sac larvae (pre-flexion) on day of

634 hatch (5.5 mm SL, $5 \mathrm{dpf}$ ). B: Yolk sac larvae (post-flexion) several days after hatch $(5.5 \mathrm{~mm}$

635 SL, 8 dpf). C: Older yolk sac larva - cranial lateral line canals have started to develop (7 mm SL,

$63612 \mathrm{dpf})$. D: Juvenile after release from mother's mouth (14 mm SL, $29 \mathrm{dpf}$ ).

637

Fig. 3. MicroCT images of adults of the three study species. A: Labeotropheus fuelleborni ( $\sim 80 \mathrm{~mm}$ SL, narrow canals; $1 \mu \mathrm{m}$ resolution). B: Metriaclima zebra $(\sim 92 \mathrm{~mm} \mathrm{SL}$, narrow

640 canals; $18 \mu \mathrm{m}$ resolution). C, D: Aulonocara baenschi (86 mm SL, widened canals; $16 \mu \mathrm{m}$

641 resolution). A-C: 3-D volume rendering in ventral view showing the MD, PO and IO canals.

642 Asterisks $(*)$ indicate the location of the canal neuromasts in the MD canal, which is contained in

643 the dentary and angulo-articular bones (in A and B) and the canal neuromasts in the MD canal as

644 well as in the lower arm of the L-shaped PO canal (in C). D: Transverse slice (16 $\mu \mathrm{m}$ thickness)

645 of Aulonocara baenschi at the level of the lens of the eye (e), indicating the lumen of the SO

646 canal and the $\mathrm{PO}, \mathrm{IO}$ and $\mathrm{SO}$ canals.

648 Fig. 4. Scanning electron microscopic (SEM) images illustrating canals and neuromasts of

649 larval and juvenile Labeotropheus fuelleborni. A: Yolk sac larva (10 dpf) with very small

650 presumptive canal neuromasts (arrows), and grooves (Stage II) of developing mandibular (MD) 
For J. Morphol., February 8, 2014

651 and preopercular (PO) canals, $\mathrm{n}=$ naris. B: Enlargement of $\mathrm{PO}$ groove in A indicating oval canal

652 neuromasts (white arrows) and two neuromasts that will remain superficial (black arrows). C:

653 Early juvenile (17 dpf) with rostral portion of IO canal (in lacrimal bone), SO and PO canals that

654 are enclosed. The other neuromasts of the IO canal series along the ventral and caudal

655 boundaries of the orbit are still superficial (arrows). The supraorbital (SO) and preopercular (PO)

656 canals are already enclosed and have pores. Lower jaw had been removed. D: Rostral-most IO

657 neuromast (at asterisk in C) demonstrating oval shape and narrow sensory strip containing

658 sensory hair cells each with a long kinocilium and shorter stereocilia (white strands). Double

659 arrow indicates hair cell orientation. Neuromast is surrounded by squamous epithelial cells with

660 prominent microvillar ridges. Scale bars in $\mathrm{A}, \mathrm{C}=500 \mu \mathrm{m} ; \mathrm{B}=100 \mu \mathrm{m} ; \mathrm{D}=10 \mu \mathrm{m}$.

661

662 Fig. 5. Scanning electron microscopic (SEM) images illustrating enclosure of canals and

663 pores in Labeotropheus fuelleborni. A: Dorsal view of the head in a late stage larva (12 dpf),

664 showing grooves of partially enclosed bilateral supraorbital (SO) canals. $n=$ naris. B: Ventral

665 view of mandible in a young juvenile (17 dpf) showing neuromast (left most arrow) and

666 developing canal. C: Dorsal view of head of young juvenile (17 dpf) showing naris (n) and SO

667 canal pores medial to naris and orbit (arrows). Superficial neuromasts (sn) are visible between

668 the left and right SO canals. Note double pore at dorsal midline (mp). D: Dorsal view of head in

669 larger juvenile (20 dpf), with labeling as in C. The fusion of the double pore (in C) forms a single

670 median pore (mp). E: Lateral view of enclosed SO PO, and IO canals with single and double

671 pores (arrows) in a $56 \mathrm{dpf}$ juvenile. F: Lateral view of a $70 \mathrm{dpf}$ juvenile in which the double

672 pores in $\mathrm{E}$ (arrows) have fused to form smaller, single pores. Scale bars in $\mathrm{A}=300 \mu \mathrm{m} ; \mathrm{B}=150$

$673 \mu \mathrm{m} ; \mathrm{C}=250 \mu \mathrm{m} ; \mathrm{D}, \mathrm{E}=500 \mu \mathrm{m} ; \mathrm{F}=600 \mu \mathrm{m}$. 
For J.Morphol., February 8, 2014

Fig. 6. Development of individual canal segments at the level of canal neuromasts in the MD

676 canal in two species with narrow and widened lateral line canals. See text for more explanation.

677 A-E: Labeotropheus fuelleborni (narrow canals, 17-70 dpf), F-J: Aulonocara baenschi (widened

678 canals, 17-47 dpf). A, F: Stage I - neuromasts sits flush with epithelium, b, g) Stage IIa -

679 neuromast sits in epithelial depression. C, H: - Stage IIb - neuromast sits in epithelial groove

680 between ossified canal walls (pink = ossified bone). D, I: - Stage III - neuromast enclosed by soft

681 tissue, E, J) - Stage IV - neuromast enclosed in ossified canal segment. m -Meckel's cartilage

682 (turquoise) in A and other images. Arrows point to center of hair cell population in each

683 neuromast. Note the much larger canal diameter in $\mathrm{J}$ (Aulonocara, $47 \mathrm{dpf}$ ) when compared to $\mathrm{E}$

684 (Labeotropheus, $70 \mathrm{dpf}$ ). Scale for all images (as in $\mathrm{J})=100 \mu \mathrm{m}$.

685

Fig. 7. Rates of increase in A: canal diameter, B: neuromast length, C: neuromast width

687 relative to fish size (SL) in Labeotropheus fuelleborni and Metriaclima zebra (both with narrow

688 canals) and Aulonocara baenschi (widened canals) derived from histological material (raw data,

689 not log transformed is illustrated). Each data point is the mean of left and right for each

690 neuromast or canal diameter, and data for SO and MD canals are combined. See Tables 2 and 3

691 for statistical analyses of log transformed data (where warranted).

692

693

694

695 
TABLE 1. Mean fish size and minimum canal diameter at which individual canal segments in the supraorbital (SO) and mandibular (MD) canals are enclosed (Stage III) and ossified (Stage IV) derived from histological material. Ascending values of mean fish size at enclosure and ossification among segments within a canal series are used to infer the order of canal enclosure and ossification within that canal (see text for additional details).

\begin{tabular}{|c|c|c|c|c|c|}
\hline \multirow[b]{2}{*}{ Species } & \multirow[b]{2}{*}{ NM } & \multicolumn{2}{|c|}{ Enclosure (Stage III) } & \multicolumn{2}{|c|}{ Ossification (Stage IV) } \\
\hline & & $\begin{array}{l}\text { Mean Fish Size } \\
\quad(\mathrm{mm} \text { SL) }\end{array}$ & $\begin{array}{c}\text { Min. Canal } \\
\text { Diameter } \\
(\mu \mathrm{m})\end{array}$ & $\begin{array}{l}\text { Mean Fish Size } \\
\quad(\mathrm{mm} \mathrm{SL})\end{array}$ & $\begin{array}{c}\text { Min. Canal } \\
\text { Diameter } \\
(\mu \mathrm{m})\end{array}$ \\
\hline Labeotropheus & SO1 & 11.8 & 78.4 & 19.0 & 99.1 \\
\hline \multirow{9}{*}{ fuelleborni } & $\mathrm{SO} 2$ & 10.9 & 79.9 & 14.8 & 119.4 \\
\hline & $\mathrm{SO} 3$ & 10.3 & 106.8 & 14.2 & 77.5 \\
\hline & $\mathrm{SO} 4$ & 8.5 & 103.3 & 13.9 & 81.1 \\
\hline & SO5 & 12.0 & 66.8 & 14.2 & 86.5 \\
\hline & MD1 & 11.6 & 98.6 & 16.3 & 82.8 \\
\hline & MD2 & 10.9 & $36.7 *$ & 15.5 & 102.9 \\
\hline & MD3 & 12.0 & 93.9 & 16.0 & 109.4 \\
\hline & MD4 & 11.5 & 109.7 & 16.7 & 94.3 \\
\hline & MD5 & 11.8 & 93.0 & 19.0 & 97.2 \\
\hline \multirow{10}{*}{$\begin{array}{l}\text { Metriaclima } \\
\text { zebra }\end{array}$} & SO1 & 13.2 & 70.4 & 19.2 & 83.9 \\
\hline & $\mathrm{SO} 2$ & 12.3 & 102.0 & 21.0 & 176.1 \\
\hline & $\mathrm{SO} 3$ & 11.8 & 69.1 & 21.1 & 182.7 \\
\hline & $\mathrm{SO} 4$ & 9.3 & 70.1 & 16.9 & 89.7 \\
\hline & SO5 & 11.5 & 113.1 & 16.9 & 86.7 \\
\hline & MD1 & 13.7 & 89.1 & 17.0 & 108.4 \\
\hline & MD2 & 12.0 & 85.9 & 21.0 & 169.9 \\
\hline & MD3 & 10.8 & 97.3 & 20.7 & 113.6 \\
\hline & MD4 & 11.3 & 124.8 & 20.7 & 122.7 \\
\hline & MD5 & 11.4 & 121.3 & 20.7 & 161.3 \\
\hline \multirow{10}{*}{$\begin{array}{l}\text { Aulonocara } \\
\text { baenschi }\end{array}$} & SO1 & 16.1 & 125.9 & 19.0 & 98.2 \\
\hline & $\mathrm{SO} 2$ & 14.8 & 130.3 & 19.9 & 249.4 \\
\hline & $\mathrm{SO} 3$ & 13.7 & 111.5 & 18.5 & 183.2 \\
\hline & $\mathrm{SO} 4$ & 9.0 & 67.1 & 16.8 & 93.7 \\
\hline & SO5 & 9.3 & 93.0 & 17.5 & 154.8 \\
\hline & MD1 & 16.2 & 134.7 & 21.7 & 194.0 \\
\hline & MD2 & 16.9 & 115.5 & 15.7 & 166.0 \\
\hline & MD3 & 10.5 & 118.8 & 18.2 & 136.3 \\
\hline & MD4 & 13.7 & 131.1 & 19.9 & 157.4 \\
\hline & MD5 & 13.5 & 128.8 & 20.2 & 160.5 \\
\hline
\end{tabular}

\footnotetext{
* obvious outlier
} 
TABLE 2. Results of ANCOVA's for mean (left/right) canal diameter, neuromast length and neuromast width ( $\mu \mathrm{m})$ for both SO and MD canals (combined) in the three study species. All data was log transformed to achieve normality. SL = Standard length (fish size) in $\mathrm{mm}$. Significance $=P<0.05$. See Table 3 for ANOVA results. If the interaction term for the ANCOVA was significant (indicating heterogeneity of slopes), the Johnson-Neyman technique was used to determine the region of non-significance for fish size (SL). See text for additional details.

\begin{tabular}{|c|c|c|c|c|c|}
\hline & $N$ & $R^{2}$ & $F$ & d.f. & $P$-value \\
\hline Canal Diameter & 280 & 0.77 & & & \\
\hline Species & & & 104.0364 & 2,274 & $<0.0001$ \\
\hline SL & & & 360.3079 & 1,274 & $<0.0001$ \\
\hline Species x SL & & & 17.9530 & 2,274 & $<0.0001$ \\
\hline Neuromast Length & 312 & 0.70 & & & \\
\hline Species & & & 59.6912 & 2,306 & $<0.0001$ \\
\hline SL & & & 221.3197 & 1,306 & $<0.0001$ \\
\hline Species x SL & & & 46.1167 & 2,306 & $<0.0001$ \\
\hline Neuromast Width & 312 & 0.75 & & & \\
\hline Species & & & 81.7744 & 2,306 & $<0.0001$ \\
\hline SL & & & 356.7013 & 1,306 & $<0.0001$ \\
\hline Species x SL & & & 24.2879 & 2,306 & $<0.0001$ \\
\hline
\end{tabular}


TABLE 3. Results of ANOVA showing ontogenetic trends for mean (left/right) canal diameter, neuromast length and neuromast width $(\mu \mathrm{m})$ of SO and MD canals combined in the three study species. All data was log transformed to achieve normality. SL = standard length (fish size) in mm. See Table 2 for results of ANCOVA for these data. Significance level $=P<0.05$.

\begin{tabular}{lcccc}
\hline & $N$ & Regression & $\mathbf{R}^{2}$ & $\boldsymbol{P}$ \\
\hline Canal Diameter & 77 & $\log \mathrm{Y}=1.759+0.022 * \mathrm{SL}$ & 0.36 & $<0.0001$ \\
Labeotropheus & 80 & $\log \mathrm{Y}=1.858+0.018 * \mathrm{SL}$ & 0.53 & $<0.0001$ \\
$\begin{array}{l}\text { Metriaclima } \\
\text { Aulonocara }\end{array}$ & 123 & $\log \mathrm{Y}=1.781+0.033^{*} \mathrm{SL}$ & 0.80 & $<0.0001$ \\
\hline Neuromast Length & 77 & $\log \mathrm{Y}=1.718+0.016 * \mathrm{SL}$ & 0.19 & $<0.0001$ \\
Labeotropheus & 85 & $\log \mathrm{Y}=1.623+0.015 * \mathrm{SL}$ & 0.27 & $<0.0001$ \\
Metriaclima & 150 & $\log \mathrm{Y}=1.425+0.043 * \mathrm{SL}$ & 0.80 & $<0.0001$ \\
Aulonocara & & & & \\
\hline Neuromast Width & 77 & $\log \mathrm{Y}=1.574+0.021 * \mathrm{SL}$ & 0.34 & $<0.0001$ \\
Labeotropheus & 85 & $\log \mathrm{Y}=1.497+0.029 * \mathrm{SL}$ & 0.59 & $<0.0001$ \\
Metriaclima & 150 & $\log \mathrm{Y}=1.427+0.045 * \mathrm{SL}$ & 0.78 & $<0.0001$ \\
Aulonocara & & & & \\
\hline
\end{tabular}


TABLE 4. Results of the ANCOVA for comparison of canal diameter, neuromast length and neuromast width $(\mu \mathrm{m})$ in the supraorbital (SO) and mandibular $(M D)$ canals in each of the three study species. Data was log transformed where appropriate to achieve normality. SL (Standard Length $)=$ fish size in $\mathrm{mm}$. Significance level $=P<0.05$. See Table 5 for ANOVA results. If the interaction term was significant (indicating heterogeneity of slopes), the Johnson-Neyman technique was used to determine the region of non-significance for fish size (SL). See text for additional details.

\begin{tabular}{|c|c|c|c|c|c|}
\hline & $N$ & $\overline{R^{2}}$ & $F$ & d.f. & $P$-value \\
\hline \multicolumn{6}{|l|}{ Labeotropheus } \\
\hline Canal Diameter & 77 & 0.403 & & & \\
\hline SL & & & 45.3922 & 1,73 & $<0.0001$ \\
\hline Canal & & & 5.2392 & 1,73 & 0.0250 \\
\hline SL x Canal & & & 0.0406 & 1,73 & 0.8408 \\
\hline Neuromast Length & 77 & 0.407 & & & \\
\hline SL & & & 25.8146 & 1,73 & $<0.0001$ \\
\hline Canal & & & 24.2579 & 1,73 & $<0.0001$ \\
\hline SL x Canal & & & 1.4813 & 1,73 & 0.2275 \\
\hline Neuromast Width & 77 & 0.558 & & & \\
\hline SL & & & 61.6011 & 1,73 & $<0.0001$ \\
\hline Canal & & & 26.4280 & 1,73 & $<0.0001$ \\
\hline SL x Canal & & & 5.3971 & 1,73 & 0.0230 \\
\hline
\end{tabular}

\section{Metriaclima}

Canal Diameter

$80 \quad 0.575$

SL

$94.7149 \quad 1,76$

$<0.0001$ 


\begin{tabular}{|c|c|c|c|c|c|}
\hline Canal & & & 3.6308 & 1,76 & 0.0605 \\
\hline SL x Canal & & & 4.6918 & 1,76 & 0.0334 \\
\hline Neuromast Length & 85 & 0.302 & & & \\
\hline SL & & & 32.039 & 1,81 & $<0.0001$ \\
\hline Canal & & & 2.8567 & 1,81 & 0.0948 \\
\hline SL x Canal & & & 0.3114 & 1,81 & 0.5784 \\
\hline Neuromast Width & 85 & 0.639 & & & \\
\hline SL & & & 129.9772 & 1,81 & $<0.0001$ \\
\hline Canal & & & 0.7738 & 1,81 & 0.3816 \\
\hline SL x Canal & & & 10.7873 & 1,81 & 0.0015 \\
\hline \multicolumn{6}{|l|}{ Aulonocara } \\
\hline Canal Diameter & 123 & 0.851 & & & \\
\hline SL & & & 643.0620 & 1,119 & $<0.0001$ \\
\hline Canal & & & 5.8674 & 1,119 & 0.0169 \\
\hline SL x Canal & & & 8.4776 & 1,119 & 0.0043 \\
\hline Neuromast Length & 150 & 0.868 & & & \\
\hline SL & & & 946.9223 & 1,146 & $<0.0001$ \\
\hline Canal & & & 9.2902 & 1,146 & 0.0027 \\
\hline SL x Canal & & & 6.3914 & 1,146 & 0.0125 \\
\hline Neuromast Width & 150 & 0.826 & & & \\
\hline SL & & & 668.7916 & 1,146 & $<0.0001$ \\
\hline Canal & & & 19.1464 & 1,146 & $<0.0001$ \\
\hline SL x Canal & & & 4.4107 & 1,146 & 0.0374 \\
\hline
\end{tabular}


TABLE 5. ANOVAs showing ontogenetic trends for mean (left/right) measurements of canal diameter, neuromast length and neuromast width in the supraorbital (SO) versus the mandibular (MD) canals of each of the three study species. Data was log transformed where necessary to achieve normality. See Table 4 for results of ANCOVA for these data. SL = standard length (fish size) in mm. Significance level $=P<0.05$.

\begin{tabular}{|c|c|c|c|c|c|}
\hline & & $N$ & Regression & $\mathbf{R}^{2}$ & $\boldsymbol{P}$ \\
\hline \multicolumn{6}{|l|}{ Labeotropheus } \\
\hline \multirow[t]{2}{*}{ Canal Diameter } & SO & 40 & $\log \mathrm{Y}=1.790+0.022 * \mathrm{SL}$ & 0.537 & $<0.0001$ \\
\hline & MD & 37 & $\log \mathrm{Y}=1.715+0.023 * \mathrm{SL}$ & 0.297 & $<0.0005$ \\
\hline \multirow[t]{2}{*}{ Neuromast Length } & SO & 40 & $\mathrm{Y}=43.766+4.294 * \mathrm{SL}$ & 0.281 & $<0.0004$ \\
\hline & MD & 37 & $\mathrm{Y}=41.119+2.635 * \mathrm{SL}$ & 0.274 & $<0.0009$ \\
\hline \multirow[t]{2}{*}{ Neuromast Width } & SO & 40 & $\mathrm{Y}=19.519+4.754 * \mathrm{SL}$ & 0.524 & $<0.0001$ \\
\hline & MD & 37 & $\mathrm{Y}=30.783+2.582 * \mathrm{SL}$ & 0.387 & $<0.0001$ \\
\hline \multicolumn{6}{|l|}{ Metriaclima } \\
\hline \multirow[t]{2}{*}{ Canal Diameter } & SO & 39 & $\log \mathrm{Y}=1.78+0.021 * \mathrm{SL}$ & 0.583 & $<0.0001$ \\
\hline & MD & 41 & $\log Y=1.93+0.014 * S L$ & 0.530 & $<0.0001$ \\
\hline \multirow[t]{2}{*}{ Neuromast Length } & SO & 43 & $\log \mathrm{Y}=1.624+0.017 * \mathrm{SL}$ & 0.297 & $<0.0002$ \\
\hline & MD & 42 & $\log Y=1.620+0.014 * S L$ & 0.272 & $<0.0004$ \\
\hline \multirow[t]{2}{*}{ Neuromast Width } & SO & 43 & $\log Y=1.396+0.037 * S L$ & 0.776 & $<0.0001$ \\
\hline & MD & 42 & $\log \mathrm{Y}=1.605+0.020 * \mathrm{SL}$ & 0.395 & $<0.0001$ \\
\hline
\end{tabular}




\begin{tabular}{lcccccc} 
Canal Diameter & SO & 65 & $\mathrm{Y}=-29.894+15.846 * \mathrm{SL}$ & 0.841 & $<0.0001$ \\
& MD & 58 & $\mathrm{Y}=8.986+12.582 * \mathrm{SL}$ & 0.875 & $<0.0001$ \\
\cline { 2 - 6 } Neuromast Length & SO & 75 & $\mathrm{Y}=-26.736+11.026 * \mathrm{SL}$ & 0.922 & $<0.0001$ \\
& $\mathrm{MD}$ & 75 & $\mathrm{Y}=-13.939+9.352 * \mathrm{SL}$ & 0.801 & $<0.0001$ \\
\cline { 2 - 7 } Neuromast Width & SO & 75 & $\mathrm{Y}=-30.647+12.927 * \mathrm{SL}$ & 0.833 & $<0.0001$ \\
& MD & 75 & $\mathrm{Y}=-15.264+10.984 * \mathrm{SL}$ & 0.807 & $<0.0001$ \\
& & & & & & \\
\hline
\end{tabular}




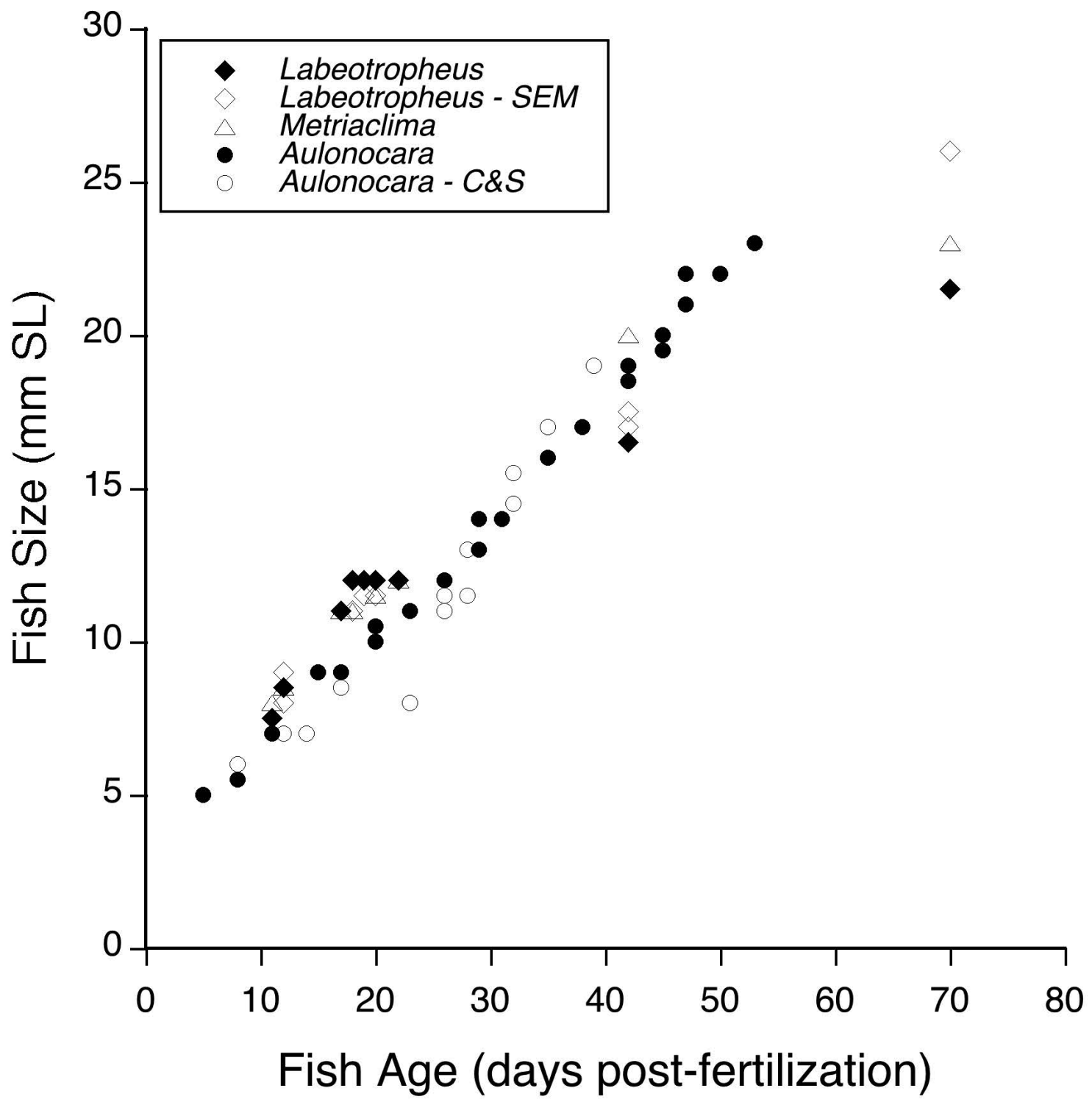

Webb et al., Figure 1 

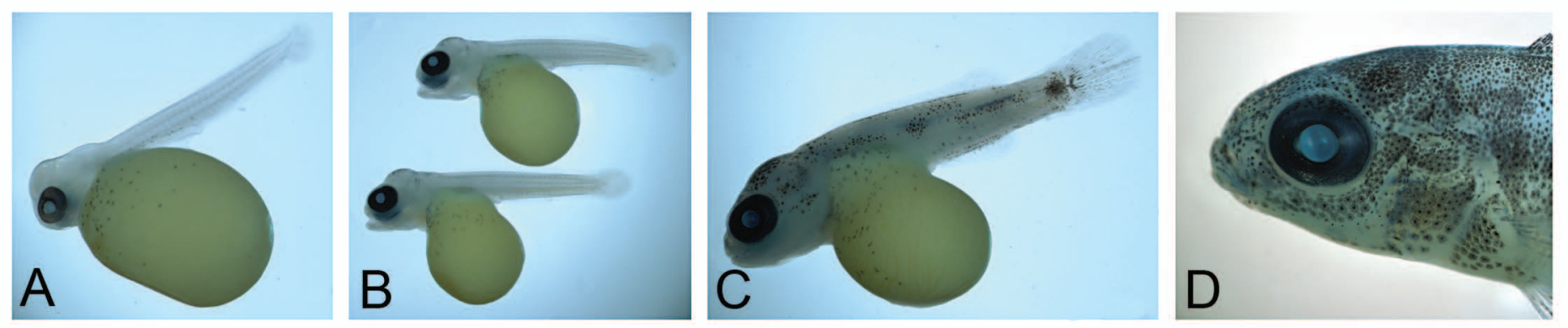

Webb et al., Figure 2. 

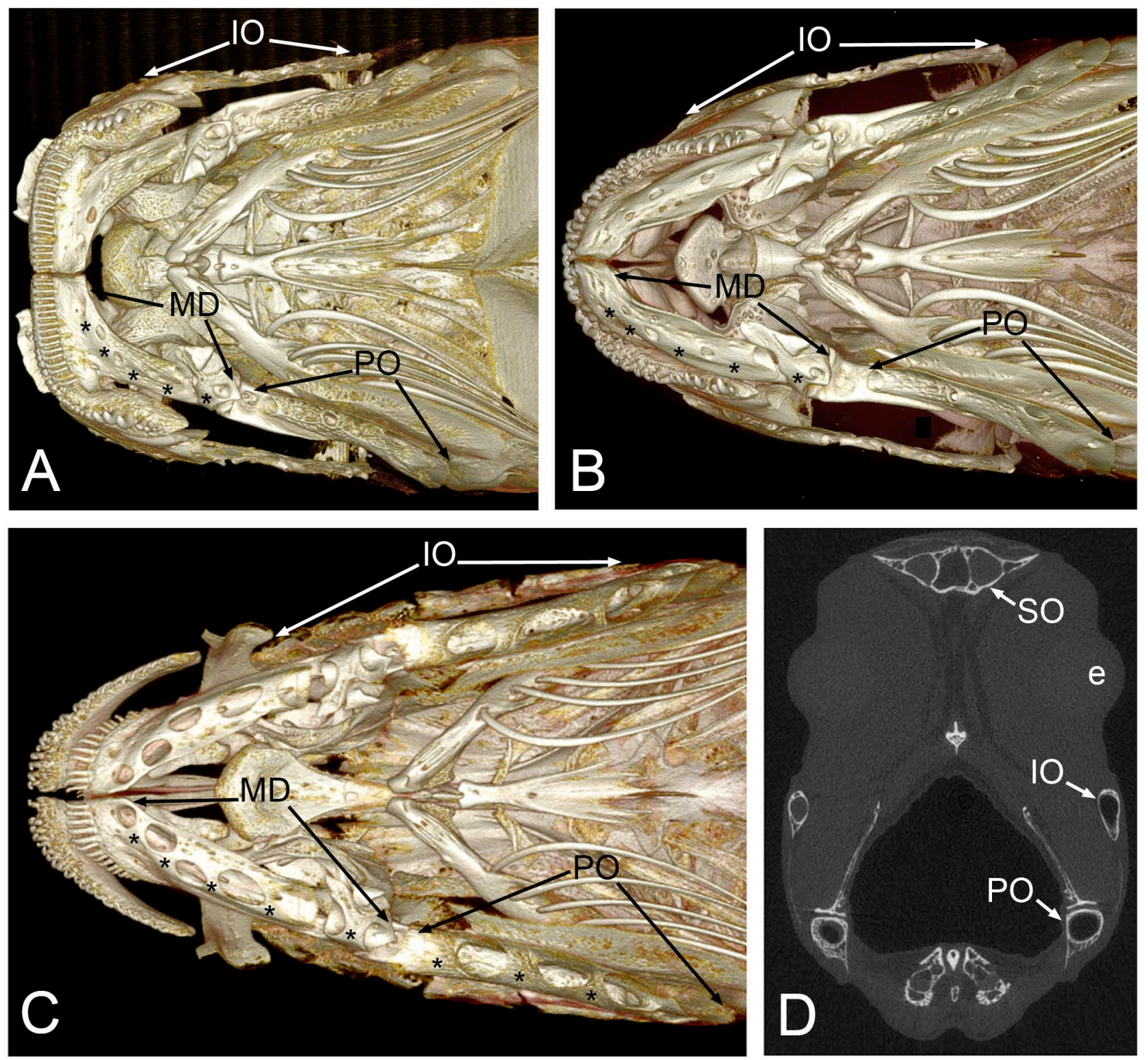

Webb et al., Figure 3 

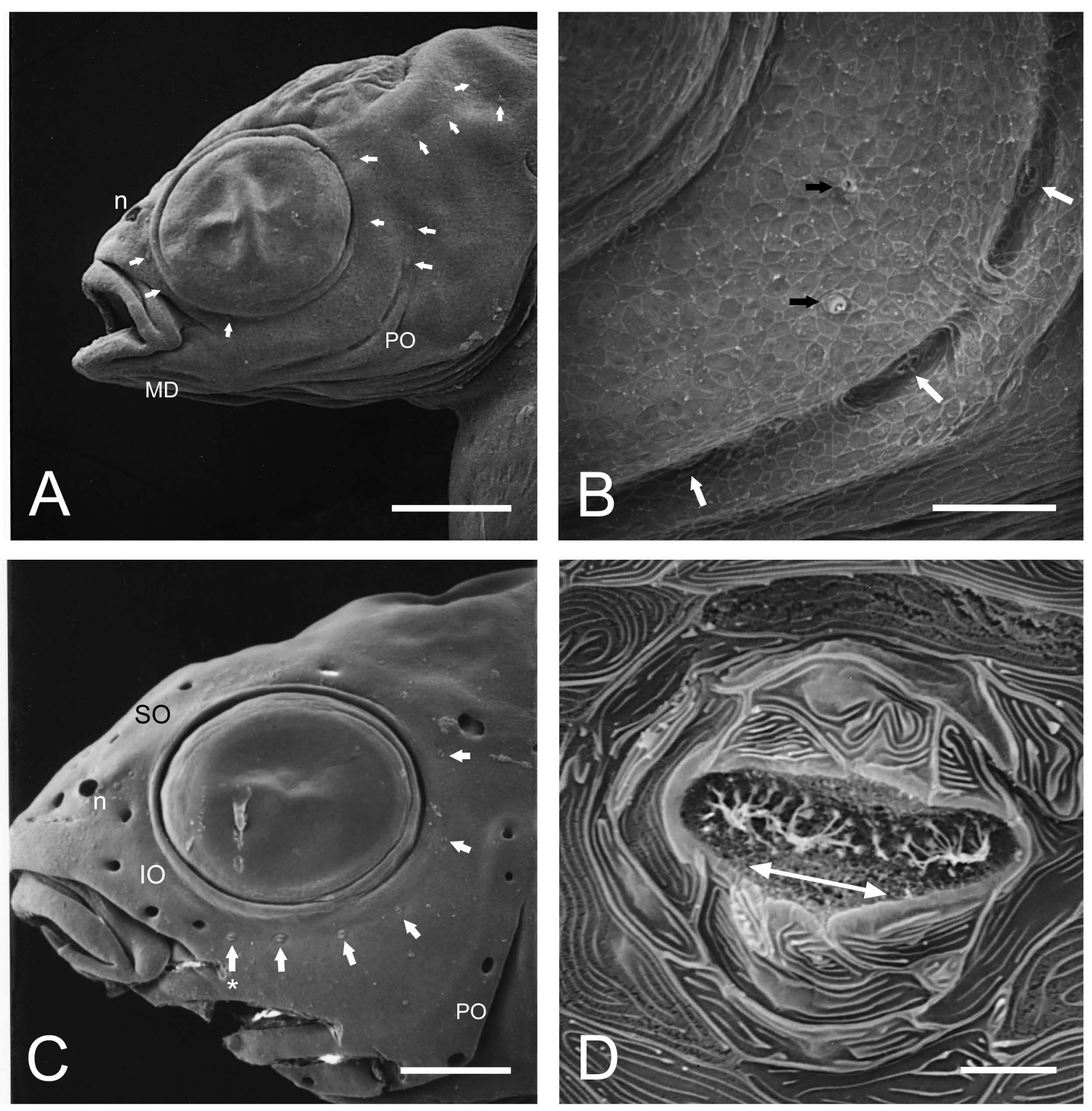

Webb et al., Figure 4 

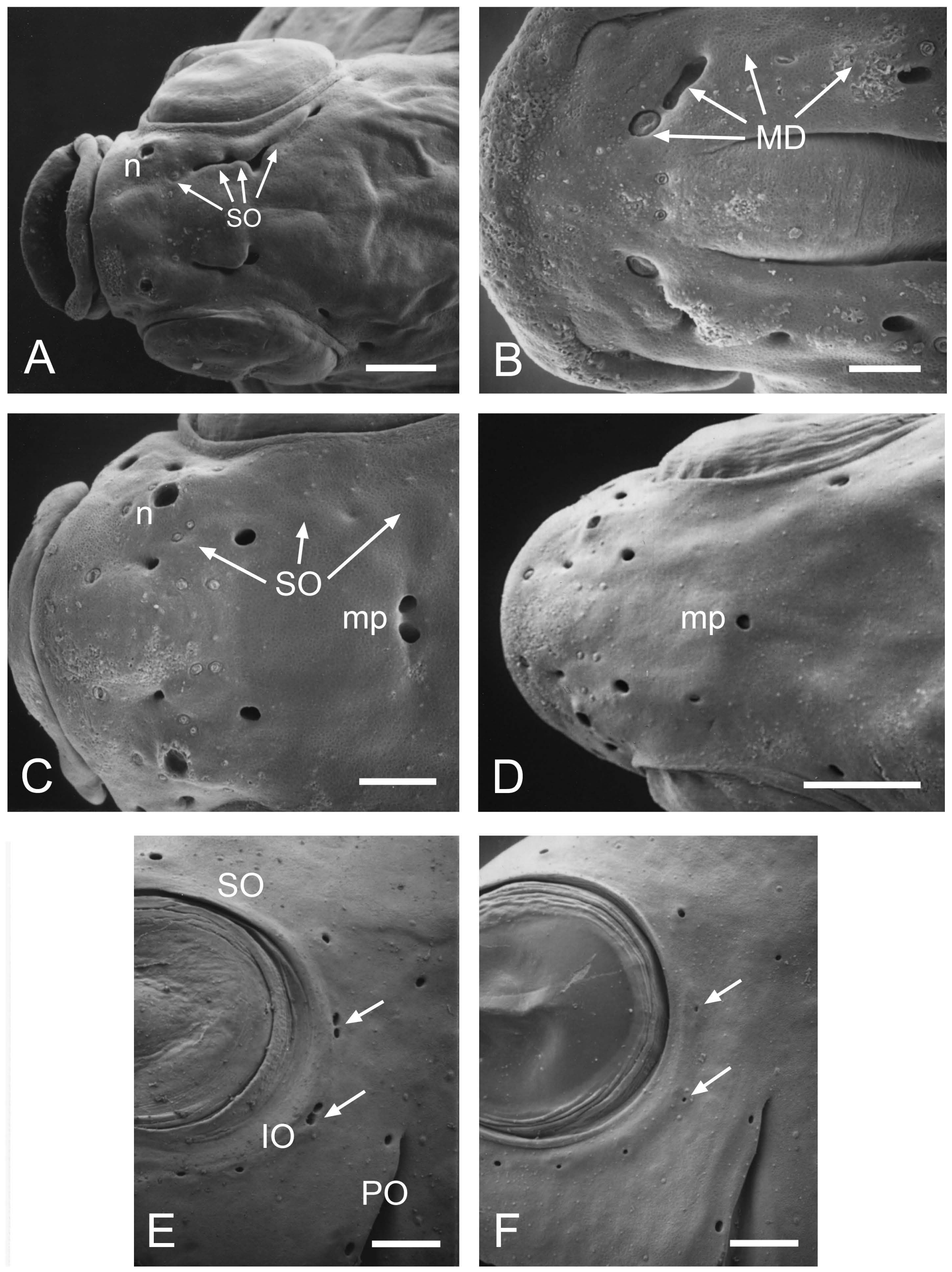

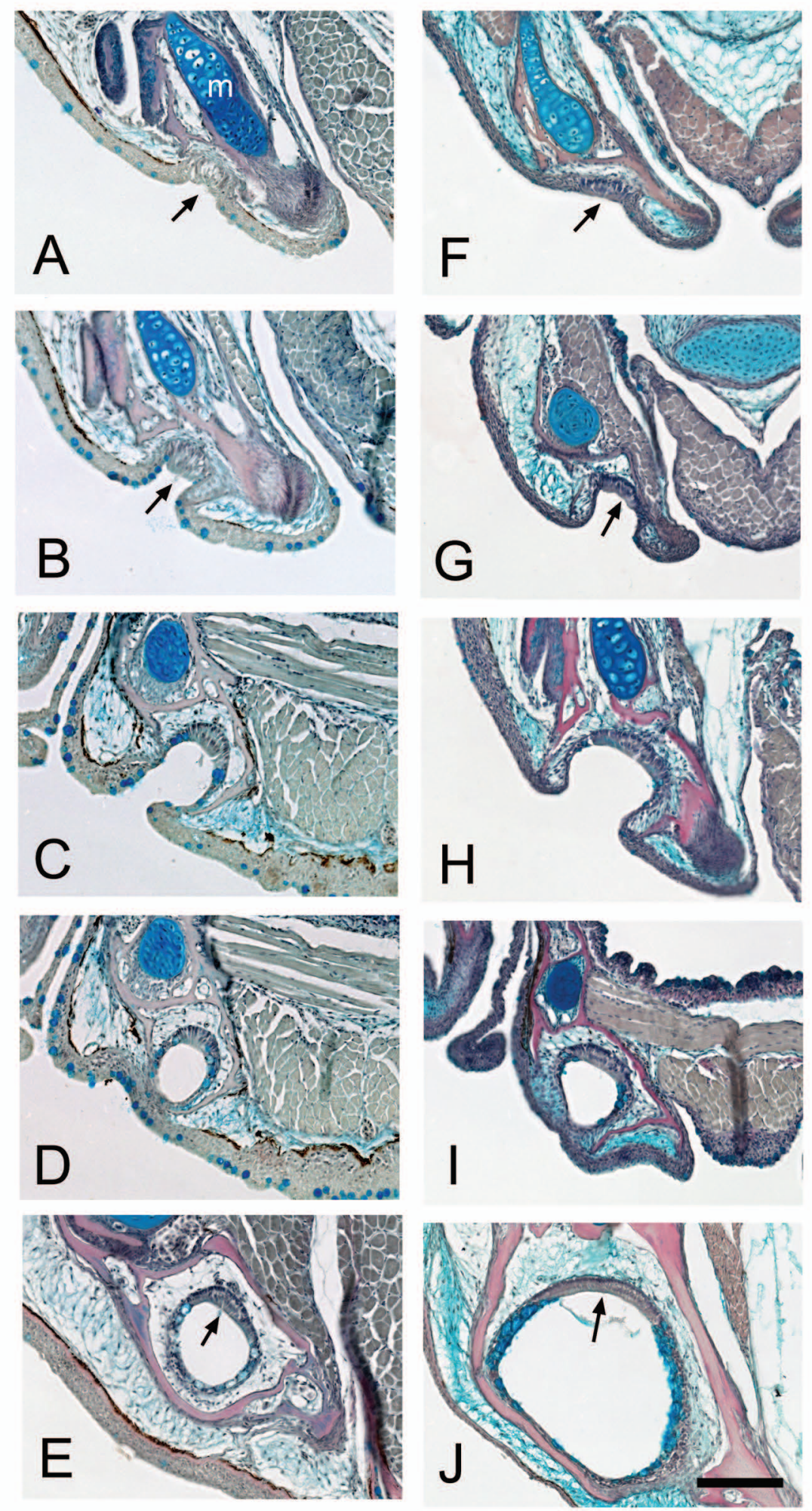

Webb et al., Figure 6 

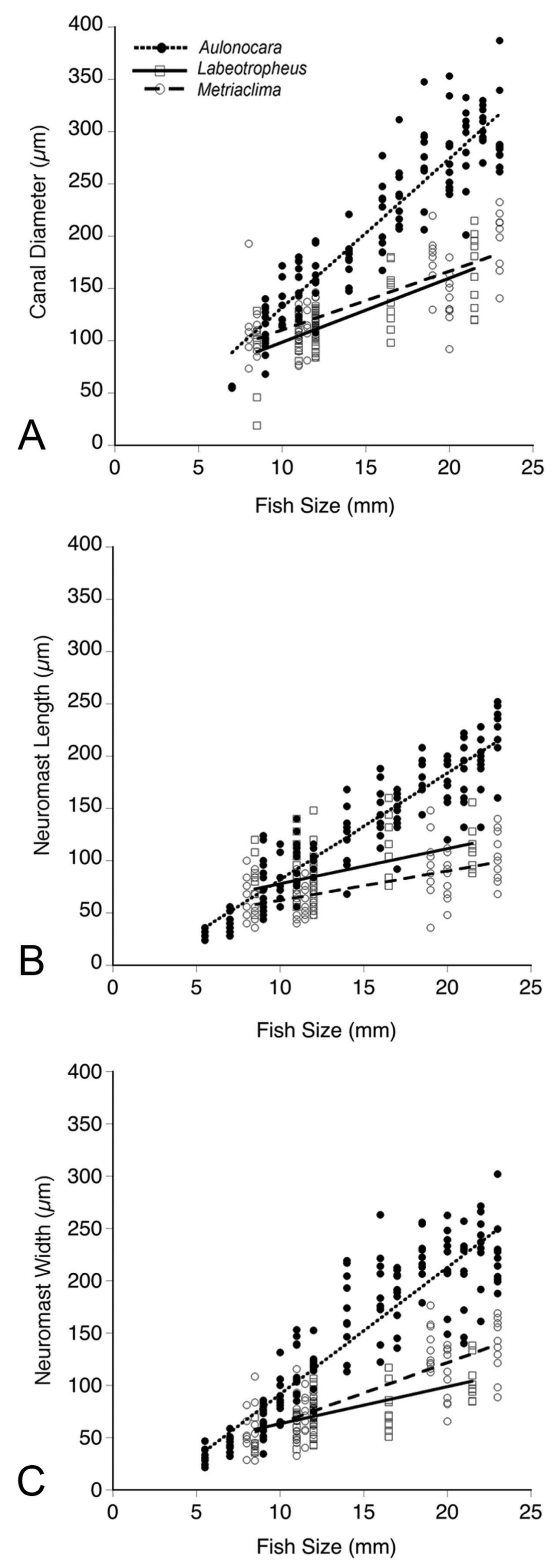

Webb et al., Figure 7 